\title{
PHILIPS HOLANDES
}

\author{
Holland Philips
}

\author{
> Camila Echeverría \\ Universidad de Los Andes, Bogotá - Colombia \\ c.echeverria393@uniandes.edu.co
}

\begin{abstract}
This work was motivated by the relationship my family has with the radio apparatus. My grand mother, her brothers and sisters, they were the first generation exposed to the radio in Colombia and always have had numerous radios in their homes to avoid loneliness, to keep informed with the news and to listen to the music. Even today, every single room at their homes has a radio on with a different transmission; some of them are transportable or mobile. An interview with my grandmother was the starting point to recognize the 2 concepts that lead the project: mobility and sound experience.
\end{abstract}

Key words: Memory - Conversation - Journey - Sound - Archive

\section{INTRODUCCIÓN}

Philips holandés es un recorrido por las sedes de las primeras emisoras Bogotanas HJN, La voz de Colombia, La voz de Bogotá, Radio Cristal o Radio Cristóbal Colón, La Voz de La Víctor, Radios Clandestinas y Ultimas Noticias, fundadas entre 1930 y 1940. A partir de los archivos sonoros de transmisiones radiales de esas emisoras, conservados en la fonoteca de RTVC (Radio y Televisión de Colombia), surge una intervención pública donde a través de una mezcla de sonidos de la época con entrevistas, se rescata la memoria de la primera generación expuesta al invento de la radio en Colombia. La intervención toma como escenario la arquitectura urbana del recorrido seleccionado (* ver mapa) y la fusiona con sonidos radiales de 1930 y 1940, invitando a los peatones de todas las edades, a conformar de manera espontánea, la audiencia a quien va dirigida.

\section{OBJETIVOS}

Philips holandés comenzó siendo una invitación personal a participar en la "Semana del Sonido" 2013 en Bogotá, con unas pautas muy claras para la realización del proyecto: recuperación de memoria usando los archivos de la fonoteca de Radio y Televisión de Colombia. A medida que fue progresando el planteamiento, fue tomando otros caminos más libres que aportaron una nueva metodología y una nueva experiencia a partir del sonido y de la acción en el Arte. El objetivo inicial que era usar los archivos, se convirtió en una excusa para descubrir la importancia de una época de oro en Colombia, los ańos 1930 y 1940. No solamente la Radio llegó en ese momento al país, el cine también estaba comenzando, sino que políticamente fue un punto de quiebre con la muerte de Gaitán que generó el Bogotazo, y en términos musicales, hubo un auge importante que abrió las fronteras del país.

A partir de los primeros resultados de la investigación, surgió una reflexión que partió del análisis de lo que ha venido pasando en Colombia con el paso de los años: La historia se borra, se ignora y se aísla de la cotidianidad, acabando con el voz a voz, cuando debería ser uno de los recursos más importantes para mantener vigentes las historias. Solamente en una conversación con mi abuela, logramos reconstruir el rol que jugó la radio en su infancia, y comprenderlo como un elemento clave que hacía girar la vida de las familias colombianas alrededor de él. Por ejemplo, las emisoras de la época sacaban los parlantes a la calle para los caminantes que no tenían radio en la casa y las reuniones familiares giraban alrededor del radio para escuchar las radio novelas. De ahí nace la fascinación por los radios de esas generaciones, un gusto que aún se conserva en silencio. Mi abuela por ejemplo, tiene un radio en cada espacio de su casa sintonizado en una emisora diferente, y uno especial que se desplaza con ella y su bastón, como su dama de compañía. De su experiencia radial, salieron los 2 conceptos que dirigieron el proyecto Philips holandés: radio móvil y experiencia sonora.

Finalmente, al enfrentar la información de mi abuela con los archivos de la fonoteca, me di cuenta no sólo del respeto y la admiración que se merece ese momento histórico, sino de la necesidad de recuperar las experiencias colectivas que marcaron esas generaciones y que en este momento prácticamente ya no 


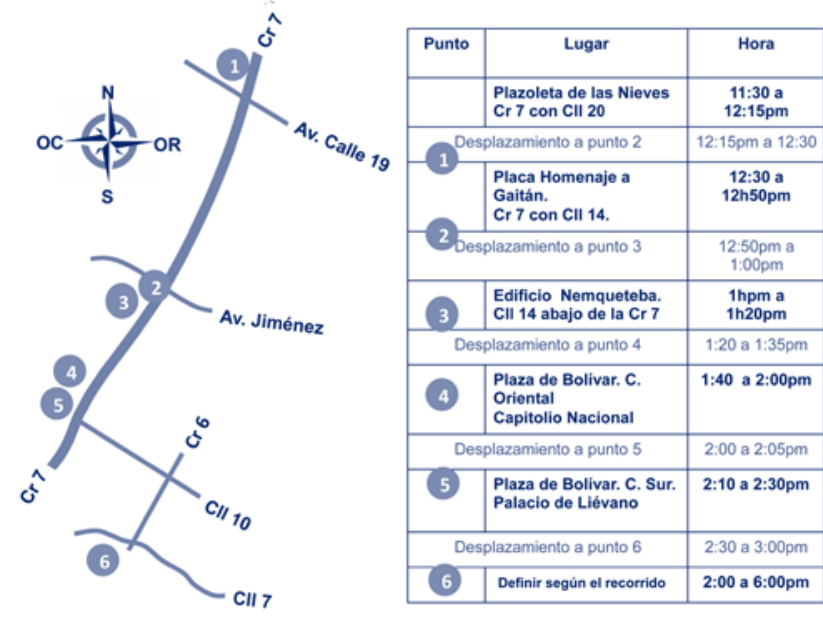

Imagen l: Mapa y programación de recorrido por las emisoras en Bogotá

existen. Por esta razón, decidí retomar la idea de sacar el radio a la calle para todos, de la radio móvil para los que aún hoy no tienen radio o ya no lo prenden. Volver a la experiencia pública y libre de circular con los sonidos que transmitían las emisoras radiales de los años 30 y 40 en Bogotá, apelando a la memoria de los que vivieron esa época y de los que podrían cuestionarse sobre el origen de lo que viven hoy.

\section{MetODOLOGÍA}

Todo comenzó con una conversación con mi abuela, una entrevista informal con la que buscaba identificar historias sobre la llegada de la radio a Bogotá y la importancia que tuvo para esas primeras generaciones con las que podemos compartir todavía hoy. De esa conversación inicial, salió el nombre del proyecto Philips holandés, es la marca del primer radio portátil que tuvo Marina en sus manos, traído desde Francia por su hija en los años 70.

El proceso creativo tuvo 3 fases que conformaron la metodología del proyecto:

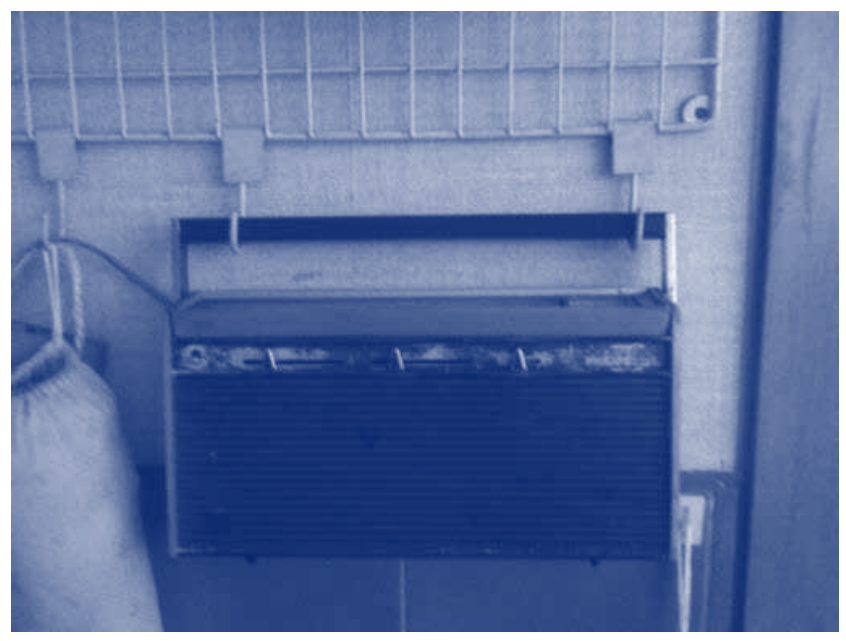

\section{IDENTIFICAR LA PROPUESTA}

Philips holandés es un recorrido por las sedes de las primeras emisoras Bogotanas HJN, La voz de Colombia, La voz de Bogotá, Radio Cristal o Radio Cristóbal Colón, La Voz de La Víctor, Radios Clandestinas y Ultimas Noticias, fundadas entre 1930 y 1940. A partir de los archivos sonoros de transmisiones radiales de esas emisoras, conservados en la fonoteca de RTVC (Radio y Televisión de Colombia), surge una intervención pública donde a través de una mezcla de sonidos de la época con entrevistas, se rescata la memoria de la primera generación expuesta al invento de la radio en Colombia.

\section{ANTECEDENTES:}

Conversación con mi abuela, recuerdos, conexión con la familia (gusto por el radio). Grabación de entrevista y sonidos de sus radios. Identificación de los conceptos: radio móvil y experiencia sonora.

\section{DESARROLLO:}

1. Archivo, investigación, acumulación de información y edición. Visita fonoteca de Radio y Televisión de Colombia en busca de los archivos radiales de 1930 y 1940 . Completar búsqueda en internet y complementar la información con historiadores especialistas en el tema. Edición de sonido.

2. Construcción de los elementos comunicadores:

- Un carrito como el que usan los vendedores ambulantes bogotanos y/o las abuelas para llevar el mercado. Se adaptó para llevar los elementos que conforman el proyecto (ver foto anexa)

- Un radio antiguo vacío para introducirle un parlante digital y montar el sonido en una USB.

- Un blog para mantener vigente el proyecto y hacerlo visible.

- philipsholandes.worpress.com

3. Realizar los recorridos en el espacio público. (ver Imagen 1)

\section{CONCLUSIONES}

Así como el proceso se fue dando a medida que las herramientas iban apareciendo, las conclusiones siguieron ese mismo ritmo. Philips holandés fue pensado para un solo recorrido y hasta el momento llevamos 5. Aunque después de cada recorrido salen nuevas conclusiones, voy a enumerar las más importantes:

1. La apropiación de símbolos colectivos como el carrito y el radio son una forma de aproximarse a la gente sin pedirles que interactúen o intervengan de manera activa.

2. El sonido tiene un fuerza particular que no había descubierto hasta el momento, le permite a los espectadores hacer parte de la intervención sin que se note. Ellos simplemente oyen y se conectan con sus recuerdos o con sus vivencias sin necesidad de compartirlo públicamente.

3. Metodológicamente trabajar con archivos y enfrentarlos a la experiencia personal, es una forma de llegar a resultados contundentes donde la originalidad y la libertad siempre van a estar presentes.

Imagen 2 :Fotografía del radio original Philips holandés. 
4. Volver a la historia y retomar momentos importantes, es una manera de entender lo que sucede hoy y lo que se ha perdido con el paso del tiempo, que vale la pena retomar.

5. El uso de recursos ya existentes, es un planteamiento que se debe tener en cuenta hoy en día en términos de leguaje plástico, de economía y sobretodo de reciclaje: 3 factores que lideran muchas de las decisiones en Arte y Diseño en el siglo XXI.

6. Cuando se trabaja una intervención pública, nunca se sabe cuál va a ser el resultado final. La incertidumbre y la sorpresa son las responsables del éxito o del fracaso.

Para terminar la presentación del proyecto, la a discusión principal que se genera alrededor de Philips holandés es revisar las capas invisibles que llevamos puestas, antes de proponer algo supuestamente "nuevo" o hablar de innovación. Todos somos el resultado de una suma de experiencias que vienen desde generaciones atrás y que a pesar de que las ignoremos o las ocultemos, siempre van a estar presentes en nuestra mirada. Todos somos archivos móviles que se activan con cierto tipo de información, materiales, sonidos, formas y esos detonantes son los que debemos aprender a identificar. Esas voces presentadas aquí como trasmisiones radiales de 1930 y 1940, son las que libremente están generando conexiones (abuela, radio, Bogotazo, memorias, recorridos) que nos llevan a diseñar una experiencia, a diseñar una estrategia para traer del

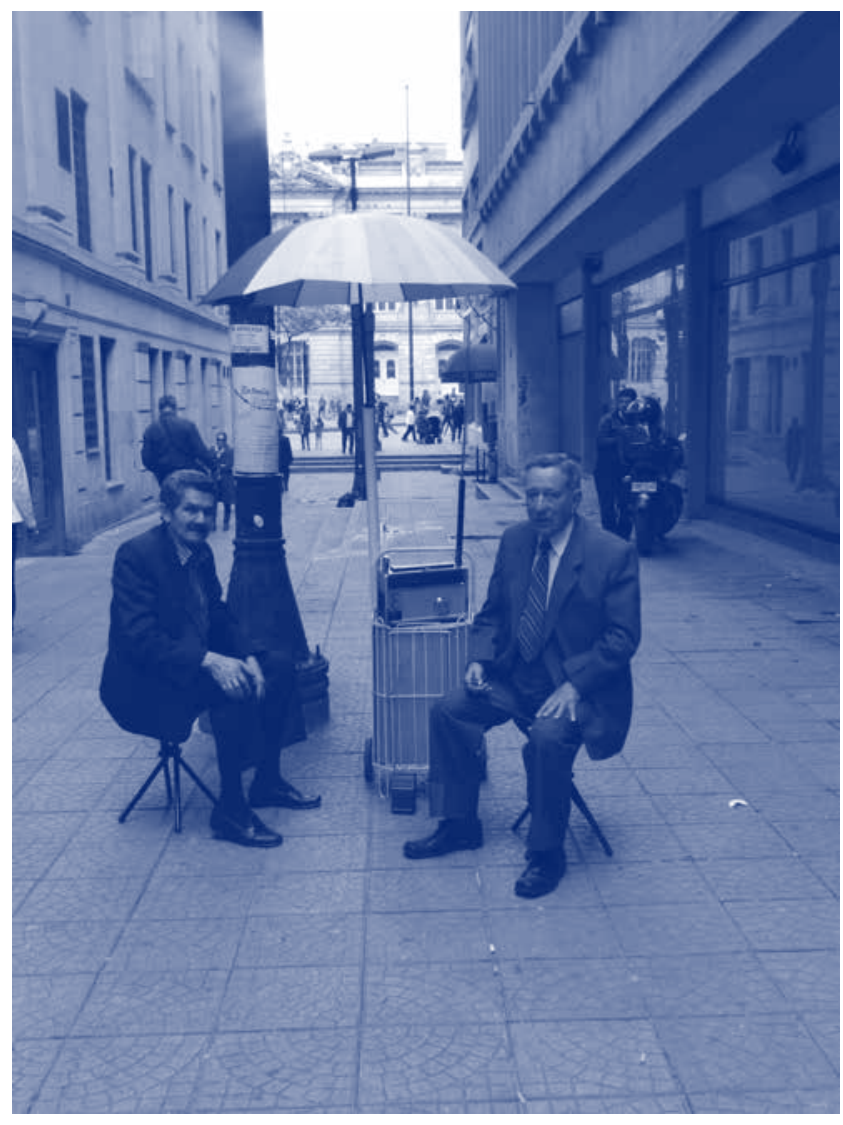

Imagen $\exists$ : Fotografía Philips holandés Calle 14 debajo de la $7 \mathrm{ma}$. pasado lo olvidado. Descubrir que una intervención urbana es lo que se necesita para poner a conversar dos tiempos que merecen ser conectados. Ya muchas de las ideas que tenemos hoy tanto los artistas como los diseñadores se han hecho, pero la pregunta no es qué hacer para solucionar esa incertidumbre sino pensar en qué necesitamos para seguir produciendo resultados que transmitan un mensaje y tengan nuevamente una voz?

\section{AGRADECIMIENTOS}

Eduardo Cote - Edición de sonido y acompañamiento en el proceso de producción.

\section{REFERENCIAS}

Radio Televisión Nacional de Colombia RTVC (2012). Historias de honda larga, Memorias de la radio en Colombia (dvd).

De Certeau, M (1984). The Practice of everyday life. University of California Press.

Kohan, M (2004). Zona urbana Ensayo de lectura sobre Walter Benjamin. Grupo Editorial Norma

Turchi, P (2004). MAPS OF THE IMAGINATION: The writer as a cartographer., Trinity University Press

Silva, A (2003). Bogotá imaginada. Convenio Andrés Bello - Universidad Nacional de Colombia

Sloterdijk , P (2008). Extrañamiento del mundo. PRE -TEXTOS

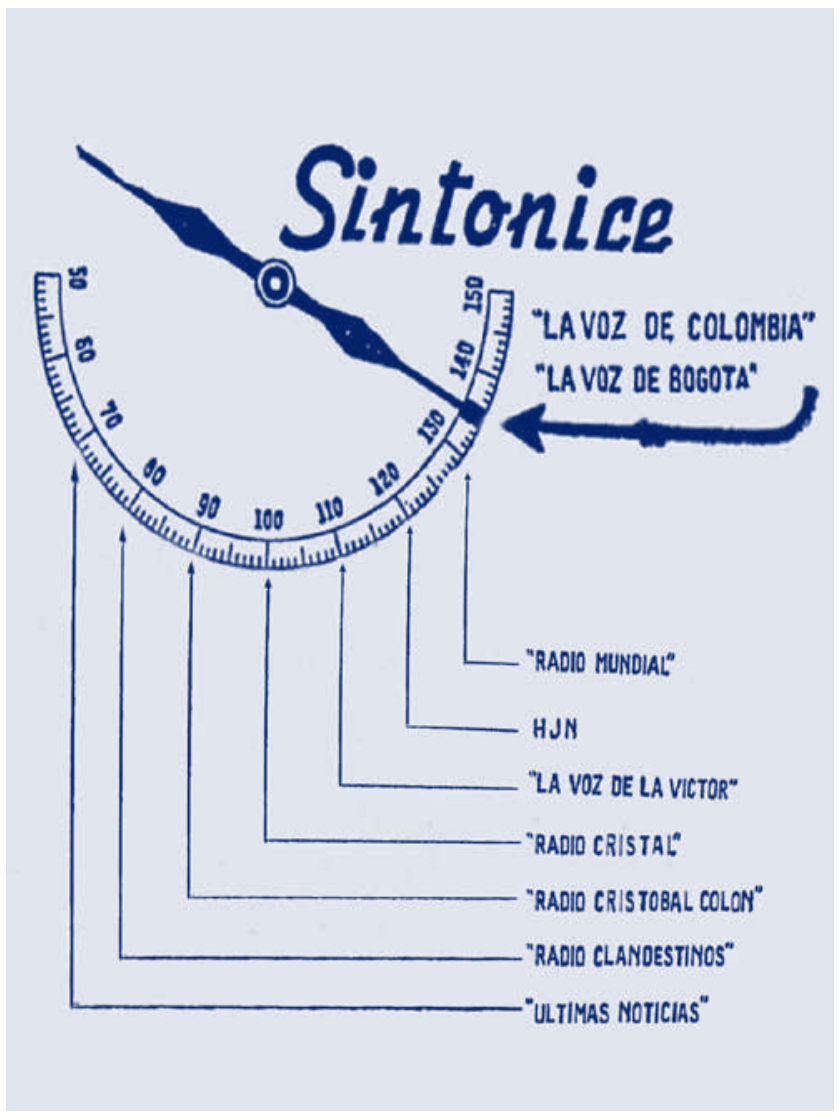

Imagen 4: Afiche con los nombres de las emisoras. 